\title{
An Evaluation of
}

Alternative \& Innovative

Regulatory Approaches

for Environmental

Management in Alberta

Prepared for:

Alberta Environment

Environmental Sciences Division

June 2000

Kemper 2 \& Associates Inc. 
Digitized by the Internet Archive in 2016 


\section{Executive Summary}

Alberta Environment (AENV), Environmental Sciences Division, commissioned an evaluation of alternative and innovative regulatory mechanisms for potential use in Alberta that would compliment the present regulatory system. A multi-stakeholder Study Advisory Committee (SAC) with representatives from the larger industrial associations, industry, government and the ENGO/public stakeholders of Alberta directed the work.

The project's first goal was to evaluate the potential for the development of an incentive based alternative/innovative approval system (AIAS) for the province that would meet the key requirements of the three main groups. The second goal was to establish the key elements of an AIAS program. AENV had determined that that any new program must reduce emissions to the environment, be acceptable to government, industry and ENGOs/public stakeholders, and be compatible within or beside the present regulatory system.

\section{Researching Experience Within Alberta and Beyond}

The work was divided into three components:

- Interview key stakeholders about the existing Alberta regulatory system, their experience with alternative or innovative approval systems (AIAS), and their ideas regarding possible AIAS for Alberta.

- Review the literature on existing programs in other jurisdictions; and

- Prepare a test model of an AIAS for piloting in Alberta.

Twenty senior professionals from industrial associations and industries, environmental non-government groups, and staff from AENV and the Alberta Energy and Utilities Board (EUB) were interviewed. Their response to the interview questions (Appendix A) indicated a general satisfaction with the current regulatory system and provided guidance on improvements which might be incentives to induce companies to perform beyond their licensed requirements. Their experience with existing voluntary programs and mechanisms indicated the weaknesses of some of the current programs. These were consistent with the findings from the literature review. Considering the comments from the three groups, it was clear that only either a regulatory mechanism or an alternative with strong regulatory backstops would meet their needs to achieve meaningful reductions in emissions.

A review of the interviews and the assessment of the current regulatory system coupled with experience in other jurisdictions provided the basis for the following core principles for a new AIA system: 
- Equal participation by government, industry and ENGOs/public to achieve win-win-win solutions.

- Open and transparent operations and decision making.

- Performance that exceeds present regulatory requirements is the baseline.

- The existing regulatory system should not be weakened by new approach, but strengthened, augmented, and refocused.

- Significant measurable environmental performance goals will be set and attained.

- Meaningful stakeholder involvement.

- Modifications to the present regulatory system should allow increased flexibility and innovation, in exchange for significant environmental benefits.

- Benefits should accrue to industry, government and the environment; these should be based on a renewed partnership embracing EMS.

- To the extent possible, use existing systems to speed implementation.

- A record of better than minimum performance to enter program.

- A mechanism to expel free riders.

\section{An Alternativellnnovative Approval System for Alberta}

The above principles and the original conditions set for the project can be met using an AIA system which is facility based (that is it deals only with the performance of a single facility) and involves the full participation of industry, government and ENGOs/public working together to establish and monitor environmental goals. The system as outlined in the report is based on company/facility environmental management systems, such as ISO 14001. This includes stakeholder participation in the establishment and on-going evaluation of beyond-regulatory performance measures. Achievement time frames, verification and audits are included to ensure public and government confidence.

Entry into the AIA system would be voluntary, but once in, companies would be required by their new license conditions to meet the established performance measures within the defined time frames. The process would be fully transparent and constitute a renewed partnership among government, industry and the public. All industry participants would commit to performing better than existing regulatory compliance using continuous improvement pollution prevention principles and defining targets for performance measures. Existing compliance requirements would remain.

To deal with the learning and experience required to develop and implement an EMS, as well as the need to adjust a company's status if goals are not met, we have proposed a three tier system with increasing responsibilities and rewards. The first tier is essentially a training level and the duration that a facility could stay at this level would be limited. The second and third tiers embrace a wider scale of impacts and emissions to the environment and call for more significant continuous improvement over time. 
Within the proposed system industry takes the lead in applying to the program once they have developed their EMS or committed internally to do so. This is consistent with the voluntary nature for entry into the program. The facility management will submit the EMS documents and a report outlining past performance and relate this to the entry criteria for the program. Once this step has been taken, the tripartite nature (government, ENGO/public, industry) of the program is engaged by government. Transparency is a prime requirement of the subsequent steps with full ENGO/public, industry and government knowledge of future events.

The lead role in administering the application falls to government, likely to a team leader who acts as a single point of contact for the AI approval.

Government provides technical assistance and interpretation to the review team, which may involve members of ENGO groups or local residents. Government assesses the application, judges the merits of the various positions and has the final responsibility to accept or reject the application. The approval is then prepared using some of the process and application documents as back up. In summary:

- Industry: Prepares EMS and AI approval application, suggests performance goals, identifies regulatory offsets, commits to and defines annual reporting, stakeholder participation.

- Government: Manages Evaluation Teams, helps set performance goals, evaluates the need for offsets, other administrative aspects, and revises the approval for the facility.

- ENGOs/public: Participates in evaluation of application with industry and government, provides evaluation of goals attainment, annual reports, and recommends new performance measures for Tier $2 \& 3$.

Under this system, all three parties would share responsibility for ongoing monitoring of the agreement, performance assessments, etc. throughout the term of the agreement.

\section{Next Steps}

Based on the SACs response to these findings, there is sufficient support to advance to a pilot stage and test the various principles and procedures. A small working group, with membership from the three groups (government, industry and ENGOs), will develop the necessary materials for piloting the program in several industry sectors. The Study Advisory Committee will continue to provide overall study direction. 


\section{Table of Contents}

Executive Summary ............................................................................................................................. i

Table of Contents ................................................................................................................................ iv

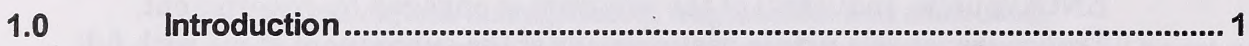

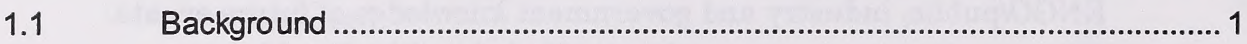

$1.2 \quad$ Purpose of Alternative/Innovative Systems ................................................... 1

1.3 Methods and Approaches to the Issues ........................................................ 2

2.0 Assessment of Current Alberta Environment Regulatory Strategy .............. 3

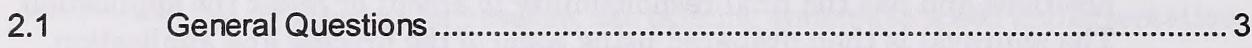

2.2 Sector Specific Questions dealing with the current Regulatory System........... 7

3.0 Experience with Existing Voluntary Systems of Management .................... 13

3.1 Experience with Voluntary Initiatives ............................................................ 13

3.2 Factors Motivating Voluntary Initiatives ....................................................... 14

3.3 Assessment of Voluntary Initiatives .............................................................. 14

4.0 Review of Alternative/Innovative Approaches in Other Jurisdictions........ 17

4.1 Accelerated ReductionElimination of Toxics (ARET) ................................... 17

$4.2 \quad$ Voluntary Challenge Registry (VCR) ........................................................ 18

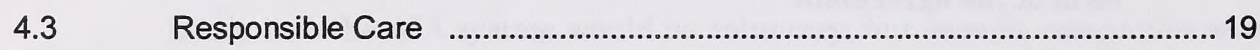

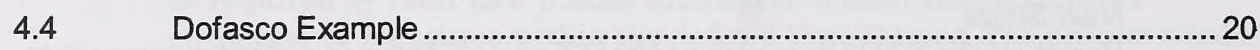

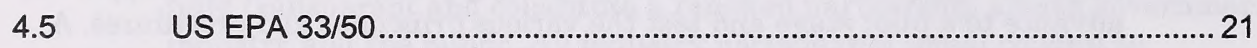

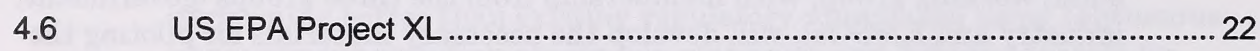

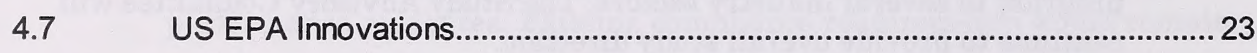

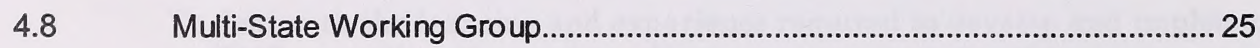

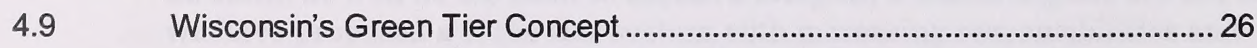

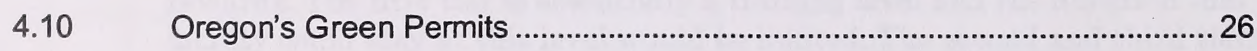

4.11 Netherlands - Environmental Covenants ................................................ 27 


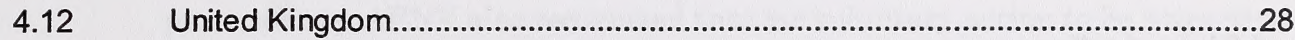

4.13 Germany - Greenhouse Gas Reduction .........................................................29

4.14 Australia - State of Victoria's Environmental Improvement Plans (EIP) ............29

4.15 Key Components of Existing Programs..............................................................30

5.0 Designing an Alberta Approach to Alternative/lnnovative Approvals (AIA) 33

5.1 Key Features of an Innovative Approach ……....................................................

5.2 Core Principles for an Alberta Alternative/Innovating Approval System ...............35

5.3 Important Trade-Offs And Limitations..................................................................

5.4 Benefits of Alternative \& Innovative Approaches .................................................36

6.0 A Proposed Alternative \& Innovative Regulatory Model for Alberta. ................39

6.1 Roles \& Responsibilities Within an Al Approval Program ....................................40

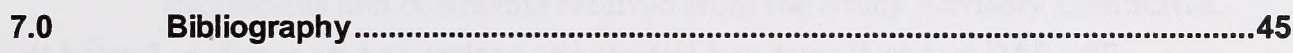

Appendix A. Interview Questions..............................................................................................49

Appendix B - Glossary of Terms and Acronyms................................................................55 


\subsection{Background}

Alberta Environment (AENV), Environmental Sciences Division, commissioned this report to examine alternative and innovative regulatory mechanisms for potential use in Alberta. The work was directed by David Spink and George Murphy from the Division as well as by a multistakeholder Study Advisory Committee (SAC). The members of the committee are listed in Section 1.4 below.

The work was divided into three components:

- Interview key stakeholders about the existing Alberta regulatory system, their experience with alternative or innovative approval systems (AIAS), and their ideas regarding possible AIAS for Alberta.

- Review the literature on existing programs in other jurisdictions; and

- Prepare a test model of an AIAS for piloting in Alberta.

The SAC met to discuss and initiate the project and its members formed the core of the interviewee pool. They also met to discuss the results of the interviews and literature survey and to consider the proposed model for piloting in Alberta. This report summarizes the results of the three components indicated above, including the suggestions from the SAC review.

Future work could include piloting an AIAS model in several different regulated industrial sectors in Alberta, assessing the results of this test, refining the model and recommending a program for implementation in Alberta.

Section 2 of the report describes interviewee's experiences and perceptions of the current AENV regulatory system and Section 3 outlines their views on alternative means of industry emission control. The fourth section, based on a literature review, describes and provides comments on the existing alternative/voluntary regulatory systems elsewhere. In the fifth section the results of the interview questions about possible alternative mechanisms for Alberta are presented, and Section 6 details a proposed alternative regulatory mechanisms for possible testing in Alberta.

\subsection{Purpose of Alternative/lnnovative Systems}

Alberta Environment, in support of the provincial government's commitment to an effective and up-to-date legislative/regulatory regime, recognized the need for an enhancement to its existing regulatory system. The purpose of the enhancement would be to recognize voluntary actions that resulted in superior environmental performance among regulated companies and to encourage all regulated companies to improve their environmental 
performance. AENV also recognized that for voluntary action to be attractive to regulated companies, the enhancement would also have to reduce the administrative regulatory burden on those companies and facilities that have a history of superior performance. Such an enhanced environmental management system would likely allow AENV staff to focus more of their resources on companies and facilities that need to improve their performance. The intent of any AIAS is to improve environmental performance while maintaining a strong regulatory framework as a back up.

\subsection{Methods and Approaches to the Issues}

To test the various aspects of the concept being posed by Alberta Environment, 21 survey questions were drafted, reviewed with AENV and the SAC and then distributed to the interview candidates in advance of the interview (Appendix A). Interviews were tape-recorded and the tapes were transcribed and forward to those interviewed for their review and comment. The revised transcripts were used for the analysis.

The input from all sources was then condensed and summarized in Sections $2,3 \& 4$, according to the original terms of reference for this work and the suggestions and comments received from the Study Advisory Committee.

\subsection{Study Advisory Committee (SAC)}

The consultant and AENV wish to acknowledge the contributions made to this study by the SAC. Members of the SAC are:

Alberta Environment:

David Spink, Environmental Sciences Division Jillian Flett, Compliance Division

Annette Trimbee

Chow-Seng Lui, Environmental Sciences Division

George Murphy, Environmental Sciences Division

Non-Government Organizations:

Myles Kitagawa, Toxic Watch Society of Alberta

Chris Severson-Baker, Pembina Institute - alternate, Tom Marr-Laing

Arlene Kwasniak, Environmental Law Centre

Industry:

David Pryce, Canadian Association of Petroleum Producers

Al Schulz, Canadian Chemical Producers Association

Neil Shelly, Alberta Forest Products Association - alternate Guy Wilson

Will Vandenborn, Dow Chemical Canada Inc. - alternate Ken Tsang 


\subsection{Assessment of Current Alberta Environment Regulatory Strategy}

An assessment of the current Alberta Environment (AENV) regulatory strategy and approach was conducted through interviews during the fall and winter of 1999-2000 and was based on questions selected to evaluate both the current system and test possible new innovative and alternative approaches.

The field of candidates for the interviews included industrial associations and industries, environmental non-government groups, and staff from AENV and the Alberta Energy and Utilities Board (EUB). The people interviewed are listed below:

1. Industrial Associations and Industries:

- Alberta Forest Products Association (AFPA) - Neil Shelly, Mike Woods

- Weyerhaeuser Ltd., regarding their experience with Project XL - Gary Stenberg and Guy Wilson

- Canadian Association of Petroleum Producers (CAPP) - David Pryce, Garry Mann

- Canadian Chemical Producers Association (CCPA) - Al Schulz

- Dow Chemical Canada - Wil Vandenborn, Ken Tsang

- Suncor Energy - Ken Hart, Gordon Kemp

2. Environmental Non-government Organizations (ENGO):

- Pembina Institute - Tom Marr-Laing, Chris Severson-Baker

- Toxic Watch - Myles Kitagawa

3. Provincial Government:

- Environment, Environmental. Assessment \& Strategy Division - Annette Trimbee and Laury North

- Environment, Compliance Division - Jillian Flett and Kim Lakeman

- Energy and Utilities Board, Environmental Safety \& Technical Division - Harry Lillo and Kim Eastlick.

\subsection{General Questions}

A set of four initial general questions was used at the beginning of the interview to evaluate the current regulatory system and its administration by AENV. The comments for each question are summarized individually in the sections below.

The specific questions were:

1. Generally, do approvals focus on the key environmental issues? 
2. Does the current system achieve the objectives of environmental protection and pollution control?

3. Is the system cost effective for obtaining an approval and for maintaining one?

4. Do you consider the current approval and monitoring reasonable and appropriate?

Overall the current system received very favourable rating from all of the groups interviewed.

\section{Generally, do approvals focus on the key environmental issues?}

\section{Industry Comments}

Among the nine industrial respondents, all felt that the existing system dealt with current key environmental issues and some noted that the system, through its evolution, was also effective in addressing emerging issues. One observer noted the importance of the EIA and hearing process in focusing interest on key issues, which then became elements in the approval.

It was noted that the current approvals might not do an adequate job of addressing climate change. ${ }^{1}$

\section{ENGO Comments}

Comments in this category showed a sound knowledge of the approvals system and there was general agreement that the present system was adequate but could be improved. They noted that where there were existing numerical guidelines, the system worked well, however where these values did not exist the impact of some activities tended to be ignored or not regulated closely.

\section{Government Comments}

These respondents noted the evolving nature of the system to address emerging and new issues, such as habitat conservation in the oil sands area. The need for new guidelines for VOCs, odorous compounds, and reduced sulphur compounds were specifically mentioned.

\section{Does the current system achieve the objectives of environmental protection and pollution control?}

\section{Industry Comments}

Most respondents felt that the system was doing an adequate job of pollution control although several areas for possible improvement were noted. These were:

- Waste management and waste reduction,

\footnotetext{
1 This issue may require a policy initiative before it can be addressed through approvals.
} 
- Move towards a pollution prevention (P2) approach rather than licensing based on accepted technology,

- Cumulative effects are not handled well, perhaps because we do not yet know how to manage them, and because licences are facility based.

Two areas where approvals have done a more than adequate job of improving environmental protection were mentioned. These were the establishment of the regional stakeholder based management system in northeastern Alberta, and the moves to control ambient levels of benzene.

\section{ENGO Comments}

This group felt that if meeting the environmental numerical guideline was the definition of protection the system worked well. However, in cases where incremental emissions affect airsheds or watersheds, the cumulative effects were not necessarily accounted for. The need to go back and adjust earlier approvals was also noted.

The lack of a pollution prevention basis for approvals was cited as a concern; that is reliance on best available technology vs. minimization of emissions. The need to use the precautionary principle with pollution prevention (P2) to put emissions management in front of guideline science was also mentioned.

\section{Government Comments}

Respondents noted the need for progress in the area of cumulative effects and the need to have equal application of pollution control to large and small industries.

\section{Is the system cost effective for obtaining an approval and for maintaining one?}

\section{Industry Comments}

There was a wide range of responses to this question and most of them felt the present costs were mitigated by the move to the 10-year approval cycle. A shorter approval cycle would aggravate the situation significantly.

While the cost of obtaining and maintaining an approval vary with the industrial sector and size of the facility. It would appear that the costs to renew an approval can run to about $\$ 300,000$ in the forest sector, and to about 15-24 months of person effort in the chemical sector.

Obtaining approval for an expansion is more costly and difficult to evaluate and varies for different types of facilities. Cost in the oil sands, where emissions and significant land disturbances are key issues, can run into the millions of dollars when EIA preparation, consultations, and hearings are considered.

Several important issues emerged that are likely equally important across the sectors. These include: 
1. Predictability: Predictability emerged as a more important issue than cost, particularly for expansions or new facilities. The concern is that when industry makes the decision to expand, they do so based on market and commodity prices (which fluctuate), and they have a need to complete the facility within a certain time window. They are able to estimate their cost, within reason, but extensive delays are costly, not only because they add to approval cost, but more significantly because they delay bringing commodities to market during the appropriate time in the price fluctuation cycle. In this regard CCPA noted the comparison between starting new facilities in Alberta and the United States. Alberta is reasonably attractive and competitive because of the predictability of the approval process here. Hearing delays in the USA can have significant adverse effects on plants being built. Conversely, it can be relatively easy to expand a facility in some states, compared to Alberta. Additional delays associated with appeal processes further complicate the process.

2. Canadian Environmental Protection Act and other federal legislation: The possibility of federal interference with Alberta approvals was noted in one case. This not only brings into question whether one would have an approval at all, but also adds the cost and complication of two possibly conflicting approval processes.

3. The Role of Environmental Impact Assessments (EIA): In several instances throughout the questionnaire the value of the EIA process in defining the key issues, providing a platform for discussion, and then seeing the key issues dealt with in the Albert Environmental Protection and Enhancement Act (EPEA) approval was noted. Suncor in particular felt that the investment made during its ELA process more than compensated for the time spent and the ease with which the latter stages of approval granting progressed.

\section{ENGO Comments}

Groups felt that the costs were not onerous on the companies, but there are, large mobilization costs associated with stakeholder participation in the various phases of approval granting. This issue extends to the ELA process also, although more formal mechanisms exist to recover costs in this process.

Their main concern here is a need for government to set some guidelines for public involvement and compensation in the approval renewal cycle.

\section{Government Comments}

AENV noted that it had been focusing on the cost effectiveness aspects in recent years and pointed to the application of specialized teams of staff to deal with specific approvals. Their experience suggests that in some cases expansions require as much effort as new facilities. 


\section{Do you consider the current approval and monitoring reasonable and appropriate?}

Industry Comments

All respondents believed that the monitoring requirements were reasonable and several linked the monitoring to the need for public acceptance and credibility. Links to potential AIA approaches were identified in some cases and the wisdom of reducing future monitoring was questioned, although the possibility of a change in reporting rates for exemplary facilities was identified.

One respondent noted that in the case of water emissions, the penalty for doing better than meeting requirements actually resulted in a "penalty" in that there was a reduction in license limits on the next cycle. Some concern was expressed that there was a tendency to use "standardized" monitoring requirements rather than have them tailored to the facility. In this connection the need to ensure some consistency as the department moves to a regionalized structure was noted.

\section{ENGO Comments}

This group expressed the view that very sound monitoring was absolutely essential to ensure access to high quality data with which to assess performance. There are reservations that recent reductions in staff within AENV and EUB will result in less monitoring of industry. The recent loss of confidence in monitoring and emissions at natural gas facilities was cited.

The benefit of having the same high standards applied to all facilities, rather than having the good performers carry the poorer ones was cited, particularly where voluntary initiatives were employed.

\section{Government Comments}

The need to have monitoring requirements linked to the facility's emissions and be based on sound science was emphasized. It was recognized that there was a need to keep progress with environmental cause/effects knowledge and ensure that system requirements kept pace, "there is always room to do better". The concept of "bubble" licensing and reporting for a facility was suggested as one way to improve monitoring tasks, and reward good performers.

There was some concern that backing off monitoring requirements might lead to a weakening of the credibility of the system. The EUB cited a case in which they had removed monitoring requirements and subsequently discovered that they needed to track industry emissions but now lacked the appropriate data.

\subsection{Sector Specific Questions dealing with the current Regulatory System}

Questions \#5 through 8 dealt with the specific aspects of the approval system that regulates industrial emissions to the environment. The responses are 
summarized according to the issues raised by the respondents across the entire set of four questions. The individual questions were:

5. Within the context of the existing approvals, we would like your comments with reference to the following:

a) Type and age of industry/business.

b) Duration of typical approval - impact on business/operations.

c) Do current approvals deal with air, water or land impacts?

d) Approval renewal cycle

e) Do approvals include all major pollutants (chemicals of concern) or activities? Which chemicals or activities are omitted?

f) Are current approvals based on performance measures or operational criteria? Does current approval specify total emissions or individual stack or end-of-pipe (point) limits? Is there any flexibility permitted?

g) What is the current approval emission period - annual, monthly, daily, hourly?

h) Are federal approvals required for your business or sector?

6. What are the overall pros and cons of the current system?

7. Characterize, in general, the type of emissions or activity authorized in your approval and link these to current provincial or national issues, such as:

a) Toxicity/Risk

b) Trend in emissions over recent decades

- Total volume

- Volume related to production (efficiency)

c) Environmental certification/public concerns

8. Does any part of your association membership perform well below their approval limits? If so:

a) What are the benefits of performing below the approval limit?

- Allowance for upsets?

- Reductions in monitoring effort?

b) Is there any disbenefit?

- High treatment costs?

- Reduction of allowable emissions at approval renewal?

Since these questions were focused on industry they had the most to say about the current system and the possible areas where improvements might be obtained if modification were made to the system by incorporating AIA approaches. It is important to consider that these comments have been made in the context of the consideration of potential new modifications. They do not constitute serious criticism of the present system, but rather represent areas on which improvements might be focused. 


\section{Industry Comments}

Responses to these questions were varied, due to the wide range of industrial sectors contacted, but many themes were common to most or all of the replies.

\section{Approval Period and Scope of Items Covered.}

Most facilities are now on ten-year approval cycles, which was seen as a positive step. While some industrial sectors have facility wide emissions limits, there is a tendency to still limit individual stacks or sources within the facility, thereby limiting the flexibility of the operator. Some areas reported that they still had individual water permits, distinct from the rest of their approval.

\section{Provincial \& Federal Regulation.}

Some sectors reported little federal intervention in permitting, while other noted that the Migratory Birds Convention Act, the Navigable Water Protection Act, Transport Canada and most significantly the Federal Fisheries Act had effects on their permits and licenses. The pulp and paper sector expressed the view that the federal requirements might limit flexibility if new approaches were developed.

\section{Scope of Chemicals Covered}

Generally the scope of the licenses was inclusive, although several new and emerging issue areas were identified which are not generally covered; these included CFCs, ozone precursors, and toxics in air.

\section{Effiuent Toxicity}

Inconsistencies were noted with the application of the fish toxicity test to effluents, particularly in areas where the requirement was enforced for industries downstream of large municipal discharges upon which the requirement was not enforced or applied.

\section{Ratchetting Down}

By far the most significant concern of industry with the present system is the tendency of regulators to ratchet down compliance limits to the point were facilities have little headroom which results in the possibilities of minor treatment system upsets resulting in non-compliance. Ratchetting is recognized as a by-product of the inflexibility of the present system, which is based on punitive measures rather than incentives. Industry point out that the original compliance limits were established to prevent short-term acute harm, however with ratchetted down limits, the levels were now far below those that could, in their estimation, cause harm. However the same penalties were applied with the same public relation damage occurring when limits were exceeded.

Complicating the matter of ratchetting down is the tendency to attempt to either reduce emissions while increasing production or to drive emissions 
down while production increases. Industry points out that some consideration of efficiency (which considers production) is required.

It was noted in several interviews that there is a greater tendency to increase the stringency of the water part of the license than the air aspects.

\section{Current System "Pros"}

Several respondents noted the attributes of the present system, which provides clear expectations of facilities and outlines the implications of the failure to meet these expectations. There was widespread acknowledgement of the new role which stakeholders play in the process and the benefits of their involvement. In the oil sands area, where regulators have stimulated stakeholder driven environmental management systems, there was acknowledgement of the appropriate transfer of accountability to industry that has accompanied this transition.

The move from five to ten year approvals was seen as a benefit, universally by those interviewed.

\section{Current System "Cons"}

In addition to the comments and issues summarized above several comments dealt with Alberta Environment's resourcing and regionalization. There was concern raised from several groups that the regionalization could lead to different interpretations of the same clause. Some felt that AENV attempted to apply existing license clauses too widely, often where they were not suited, and out of date clauses tended to be retained. Some industries expressed the view that there was a tendency to retain existing monitoring sites even when long histories showed that they were redundant or ineffective.

There was widespread support for government monitoring activities and support for the extension of enforcement efforts to poorer performers in the event that an AIA approach reduced some inspection effort for good performers.

The tendency for the command and control system to stifle creativity and, in some cases, prevent the achievement of the best economic and socially sustainable options was noted. Several examples were provided to illustrate that far more environmentally beneficial and cost effective solutions were available than those achieved by present regulation.

The tendency in some cases to define items as "wastes" limits the flexibility of companies to find alternate uses.

The need for more efficient electronic data filing systems was noted in several cases, although this may have been (or is being) rectified. Companies questioned the utilization of the large data inventories by government, and pointed out that modern electronic data management systems had built in 
graphing and analytical programs that would assist government and ENGOs in interpreting monitoring results.

Finally several industrial groups noted the difficulty associated with maintaining stakeholder interest and involvement in their regulatory review process over the longer term. When stakeholders are satisfied that a facility is performing properly they tend to reduce their participation. This is a problem for industry if their approval mandates regular stakeholder involvement.

\section{ENGO Comments}

These groups felt that the transition to the 10 year license, while beneficial to some, left too long a period between opportunities to review the license limits and perhaps reduce emissions, modify clauses or adjust for other new facilities impacting the same area (cumulative effects).

The concern was voiced that with both the EUB and AENV using welltrained technical staff in the role of facilitator, government had removed some of the more knowledgeable people in the public sector from the problem solving/advisory role. This was seen as particularly serious in the field of air toxics where very few experts are available.

Two issues with the present regulatory review system were raised. The first dealt with the definition of "directly affected parties" and the second with the need for stakeholder intervention to call a hearing. The implication is that if no one objects there are no environmental issues and, therefore, no need to have a hearing. ENGOs see a hearing as an opportunity to ensure that agreements reached with industry are discussed openly and codified in facility approvals. This situation has been aggravated by the tendency of government only to facilitate rather than provide technical information and advice.

ENGOs also noted that the present system is not able to handle the full scope of environmental impacts associated with a facility.

An important theme, which was repeated in the assessment of voluntary initiatives section of the questionnaire, was the need for verification of certification processes, environmental management systems (such as ISO 14000) and performance results.

\section{Government Comments}

Generally government respondents chose not to answer these questions on the basis that it is difficult to objectively evaluate your own processes. However some useful insights were provided that could guide the application of AIA approaches.

The existence of other ways of evaluating performance, including the international accreditation and certification system, was mentioned. 
In response to the concept of rewarding industry for performance above and beyond compliance requirements, it was noted that traditionally government's role is to ensure that each facility, at a minimum, meets its legislative requirements. Any AI system cannot reduce the government's ability to ensure compliance. With respect to ratchetting down, it was pointed out that typically, companies were ratchetted down to make room for other emissions (new facilities/sources). The weakness is that the tendency has been to issue licenses based on the assimilative capacity model with no knowledge of future planning for new players. This tends to complicate both the compliance and monitoring systems. 


\subsection{Experience with Existing Voluntary Systems of Management}

A series of four questions were directed to all interviewees to determine their experience with alternative or innovative approaches to pollution control either in Alberta or elsewhere. For those cases in which experience was available we tested the success or weakness of the application and the motivating factors which lead to its implementation.

The four questions were:

9. Has any segment of your industrial group participated in Innovative or Alternative approaches?

a) Where?

b) For what period of time?

c) What types of emissions or activities were involved?

d) What was the goal?

- Reduce emissions

- Internal recycling or marketing

- Internally or externally motivated or driven.

10. Was the I/A Approach successful/unsuccessful, what were the benefits/disbenefits?

11. For any existing or past I/A experiences, how important to your group were the following elements
a) Corporate acceptability/image
b) Cost
c) Market factors
d) Trade equivalency - free trade legislation
e) Comparative cost in other jurisdictions
f) Relationship to regulations
g) Financing certainty
h) Public acceptability

12. For these I/A approaches, how were the following aspects dealt with?
a) Verification of environmental outcomes / results
b) Accountability for achieving the environmental objectives
c) Communication with stakeholders and the public
d) Involvement/consultation with community and stakeholders
e) Relationship to regulations

\subsection{Experience with Voluntary Initiatives}

Alberta industries and ENGOs reported participation or knowledge of eight programs involving some form of voluntary initiative. These included:

Voluntary Challenge Program (VCR), Accelerate Reduction \& Elimination of Toxics (ARET), National Pollution Release Inventory (NPRI), Forest Care and Responsible Care $\otimes$. Recent initiatives to remove benzene from glycol dehydrator emissions and the Oil Sands Environmental Coalition/Oil Sands Industry $\mathrm{NO}_{\mathrm{x}}-\mathrm{SO}_{2} \mathrm{MOU}$ were also cited, as was the current evolving CAPP 
Stewardship Program. The characteristics and success of some of these programs, and others, are covered in the Section 4.

\subsection{Factors Motivating Voluntary Initiatives}

When questioned as to the motivating factor for the establishment of voluntary initiatives, companies invariably cite the importance of corporate image and public acceptability. Cost, market factors and competitiveness were also seen as important factors. Several firms mentioned the need to demonstrate responsible actions in the communities in which they operated.

In response to questions in this category at least two industrial groups noted the increasing importance being recently placed on independent verification of reported results. The addition of verification to Responsible Care $\otimes$ and the incorporation of Community Advisory Panels into CAPP's Stewardship program were mentioned. The AFPA used ENGOs to develop their Forest Care program that also features ENGO participation in audits.

\subsection{Assessment of Voluntary Initiatives}

The utility of the various programs to meet their goals was judged differently in industry and ENGO circles. Typically industry acknowledged the need to respond to public pressure and concern for environment and human health protection. They initiated programs to address these issues and generally they believe that the programs are doing so and are evolving to provide more credible information. The noticeable trend among the more proactive programs is the incorporation of some form of audit or independent verification of results to address the criticism that the programs are merely public relations with little benefit to the environment.

In an audit of the VCR, the Pembina Institute examined some 700 records within the program and found that only 81 made a significant commitment to reduce greenhouse gas emissions. They cited the lack of a regulatory backstop as one reason why the program would not meet its international goals for greenhouse gas reductions.

In its initial stages the ARET program sought ENGO participation, however groups such as Toxic Watch withdrew from the program early over the failure to agree on the definition of "Elimination". The program has no audit function which hampers formal evaluation of its success. The Responsible Care program, while similar in some ways to ARET, has begun full scale implementation of a three-year verification system to assess management systems performance, introducing an audit function to improve its credibility.

The recent effort to reduce benzene emissions from glycol dehydrators by Environment Canada and industry was cited as a more successful model by both industry and ENGOs. They felt that this was successful because government had clearly indicated that if the voluntary initiative were not successful, regulatory measures would eventually be put in place to achieve 
the goals. Industry believes that the environmental benefits will be achieved more quickly under the voluntary, rather than the regulatory option. 


\subsection{Review of Altemative/Innovative Approaches in Other Jurisdictions}

A literature review was conducted to determine what types of innovative and alternative approaches were being used in other jurisdictions, to assess how they functioned and to determine if there were common characteristics that affected a program's success.

It is important to note that most of the innovative/alternative programs researched were listed as "voluntary" mechanisms. Some of them were completely voluntary, while for others participation was encouraged by the potential for some sort of "or else" action or an incentive. For some once a company chose to participate, the conditions were mandatory. It is also important to note that the existing regulatory regime and the extent of initial regulatory control are different in each jurisdiction, potentially affecting the success of the alternative approaches.

Most of the existing programs are directed at either reducing greenhouse gases or reducing/eliminating toxic chemicals. They often have specific targets, such as the global and national greenhouse gas reduction goals resulting from the Kyoto Protocol. This review focuses on what alternative mechanisms have or have not been successful and why. While this includes reviewing how well a particular program is meeting its goals, there are other factors such as changes in total emissions, changes in emissions profile and government, industry and public acceptability that are also important.

\subsection{Accelerated Reduction/Elimination of Toxics (ARET)}

The ARET program arose out of the work of the New Directions Group (ARET Secretariat, 1996). The New Directions Group (NDG) came together in 1990 to establish a forum that "actively uses co-operative, non-adversarial methods of identifying and providing leadership in addressing significant environment-economy issues". The members were CEOs and executive directors from ENGOs. The first problem they tackled was to find alternative methods to reduce toxic substance emissions. Their goal was to complement, not replace, existing government regulations and industry initiatives. They challenged government to respond and Environment Canada did, by forming the ARET Committee. This committee initially had membership from industry associations, ENGOs, labour, aboriginal peoples, federal and provincial governments, and health and professional groups.

The objectives of ARET were to (1) establish criteria for defining toxicity [done], (2) compile a list of target substances based on these criteria [done] and (3) devise a means by which industry could address its toxic emissions.

The Committee set reduction goals for the various lists of target substances and of the 303 facilities that participated in the program there was a significant reduction in emissions from 1997 to 1999 (Environment Canada, 2000). The program is voluntary, but the benefits to participants include 
enhanced corporate image and competitiveness, improved employee health and safety, increased product yield because of reduced leakage and spills and a decreased potential for long-term liability. The ARET mandate ends in 2000 and they are currently evaluating various aspects before renewing.

The 1996 evaluation (ARET Secretariat, 1996) by Queens University found that the original participants had many significant concerns. The ENGOs, labour and aboriginal groups withdrew from the committee and the ARET project was transformed into the ARET Challenge, which has taken on a relatively successful life of its own. The problems with the committee centred on the lack of a clear initial mandate, the need for better facilitation and the need for stronger leadership from Environment Canada. Stakeholders need to know what the goals of the consultation process are, what is on the table for discussion. If members are not willing to negotiate then, the report suggests, government (EC) must play a role as a "motivator" for discussion. The initial ARET process was unclear as to whether the members' role was a consultative one or shared decision-making. This situation lead to differing expectations. The review also noted that unequal access to technical support and the need for some stakeholders to rely on unpaid personnel was a serious obstacle to success.

The need for a credible, verification mechanism is another significant shortcoming of the ARET Challenge. The review authors suggest mechanisms such as ISO 14000, EMS, external audits or a modification of the National Pollution Release Inventory (NPRI) to include ARET substances as some alternatives to address this problem. Overall they conclude that it is up to the proponents of voluntary mechanisms "to show that their approach can achieve as much or more than regulatory action".

\subsection{Voluntary Challenge Registry (VCR)}

The VCR web page (VCR 2000) advises that the mission and mandate of the registry is to record and document participation, action plans, best practises and achievements towards greenhouse gas emission reductions. It is also to recognize, publicize and promote participants who make significant progress towards the national objectives. In response to the criticism that many of the registrants have not actually done anything to reduce emissions, registry staff did an audit of the membership. They found that of 906 members (May 99), 370 had never submitted an action plan. These companies were notified that they must submit "the beginnings" of a plan in order to stay registered. Since then 64 have, 37 have withdrawn and there has been no response from the remaining 269. There is no indication on the web page of what action, if any, has been taken regarding these non-responders. Of the total membership, only 178 have demonstrated any progress towards emission reduction. The VCR now has different categories of recognition (bronze, silver and gold). Members are rated according to: senior management support (5 points maximum), base year quantification (12 points), emissions projections ( 7 points), target setting (10 points), measures to achieve targets ( 20 points), results achieved ( 31 points, and education, training and awareness programs 
(15 points). Bronze recognition requires 50 points, Silver, 70 points and Gold, 90 points. Verifiable results are worth 2 points and independent verification an additional 3 points.

A review of the VCR by Beaulieu (1997) indicates that companies promoted the concept of a voluntary program as an opportunity to make changes in a "cost effective way based on good business sense" rather than by regulation. She notes that a KPMG survey of 1500 companies, hospitals, municipalities, universities and school boards indicated that $93 \%$ said that compliance was a motivating factor in improving environmental performance and $25 \%$ said that voluntary programs were an important factor. She also cites a Pembina Institute for Appropriate Development (PIAD) evaluation in 1995, which found that of 587 VCR participants only 73 had included an inventory and commitment to at least one action. Of the action plans reviewed only 11 scored better than 50/100 and the top score was 60 based on PIAD's rating system.

\subsection{Responsible Care}

The Canadian Chemical Producers Association (CCPA) initiated the Canadian Responsible Care ${ }^{8}$ program in 1985. The details of the program and their annual reports are available on their web site (CCPA 2000a). The program involves six codes of practice:

- Community Awareness and Emergency Response

- Research and Development

- Manufacturing

- Distribution

- Transportation

- Hazardous Waste Management

The philosophy is one of continuous improvement, community involvement and lifecycle management. In order to improve the program itself the CCPA has commissioned an independent review and has instituted a National Advisory Panel made up of environmentalists, academics, labour, public interest advocates and members of the community. This Panel has indicated a number of concerns and improvements regarding the program, which the CCPA is now addressing. The main concern has been with a lack of verification of the results. There is some confusion regarding which aspects of the program are being verified. This was apparent in both the literature review and the interview comments. At issue is whether there is an independent audit of emissions to the environment or a verification of the implementation of the codes of practice dealing with management systems and workforce involvement.

CCPA is implementing protocols (June 1999) for a re-verification program (CCPA 2000b). This program is undertaken on the third anniversary of a company's initial Responsible Care-in-Place verification. This review emphasizes performance, confirming that management systems are 
delivering the results expected by the public. For example, Dow Chemical's recent reverification included an examination of management systems, and workforce understanding and involvement. It was conducted by an independent 4-member panel comprised of two industry representatives, one public member and one university professor.

Responsible Care $₫$ is a program that was initiated by the Canadian Chemical Producers Association, which has now been adopted by chemical producers in approximately 40 countries world wide. Internationally, the program is administered by the national chemical associations who encourage their member companies to participate, provide assistance and monitor progress.

In a review of the program for UNEP, Lever (1998) noted that the program has resulted in a wide variety of chemical companies publicly committing themselves to responsible environmental health and safety management. This, in turn, through association and public pressure is changing the industry culture thus reducing plant and product emissions to the environment. An important advantage of the program is the reduction in accidents and spills to the environment, which is a financial benefit to the companies. His report indicates significant emission reductions for different chemicals in different countries but notes that the main shortcoming is the lack of procedures to verify the actions/results of member companies. He also finds that, while there is public involvement at the association level, there also needs to be public involvement with individual companies too.

The European Chemical Industry Council (CEFIC, 2000) notes that verification has been added as one of the fundamental components of the Responsible Care ${ }^{\circledR}$ program as of 1996 but that the programs of different member countries are at different stages of development and have different emphases. The International Council of Chemical Associations, the global managing organization for Responsible Care $₫$, notes in their 1998 annual report (ICCA 2000) that performance assessment can range from internal self-assessment processes to third party verification. The report concludes that implementation of verification processes needs to be speeded up.

\subsection{Dofasco Example}

Dofasco, the Ontario Ministry of Environment (MOE) and Environment Canada (EC) signed an agreement in November of 1997 that committed Dofasco to reduce benzene and PAH emissions by more than would have been required under the steel manufacturing sectors strategic options negotiations with EC. In return, the governments will streamline Dofasco's approval process, consolidate approvals to accommodate facility modifications and process changes, and increase operational flexibility. It is assumed (Lukasik 1998) that Dofasco saw the potential for regulatory changes as a result of the steel manufacturing sector strategic options negotiations with Environment Canada and decided to pursue an agreement that would allow them a more flexible regulatory approach. $\mathrm{MOE}$ and EC were willing to participate because Dofasco has met its commitments in the past. 
Lukasik (1998) notes that this agreement has been widely criticized by the Canadian Environmental Law Association (CELA), among others. The main concern is that there is no public participation, including no input to the agreement negotiations, no accessibility to the agreement and no commitment to public reporting on their emission results. Also, she reports that CELA questions whether or not the agreement is enforceable and is concerned that moves like this frustrate attempts to level the regulatory playing field.

\subsection{US EPA $33 / 50$}

The United States Environmental Protection Agency has tried a number of different approaches to regulating and encouraging better environmental performance. This now completed program, which was started in 1988, was a voluntary effort to reduce the emissions and transfers of 17 toxic chemicals by $33 \%$ over the first 3 years and $50 \%$ by the end of the program (1995). In a review by O'Toole et al. (1997), they discuss what effect this program probably had and why.

The authors saw the $33 / 50$ program as a truly voluntary program, i.e., it had no coercive or incentive-based leverage. They note that while such programs can be effective, it is usually in unregulated areas (non-point source agricultural pollution, disease prevention, etc.). The 33/50 program appears to have made a difference, although it is impossible to control for all the other variables that could be affecting emissions. The key factors contributing to its success are communication and the cumulative effect of a number of policy instruments (O'Toole et al. 1997). Communication, especially at the regional or local level was assessed as extremely important. Participation of local regulatory staff with plant managers had a greater positive effect than head office to head office communication. The authors recommend that more refined and narrowly focused communication efforts that deal with targeted sectors and/or emissions would be beneficial in future voluntary programs. They also reported that the $33 / 50$ program was more successful in states that had some regulatory backstop. They conclude that no one element drives corporate behaviour; politics, policy, regulations and economics are all factors.

In assessing the drivers for participation in a voluntary program like $33 / 50$, Arora and Cason (1996) found that, based on an economic analysis, the firms that participated were firms that were "closer" to the final consumer and had larger advertising budgets. They concluded that if firms perceive that their consumers care about the environment (and, perhaps, are willing to pay slightly more for environmentally friendly products), then the firms are willing to participate in voluntary programs. In an earlier review of 33/50 (Arora and Cason 1995) also indicated that volunteer programs work best when some firms already over comply - thus putting pressure on others through 'environmental competition'. Public relations and advertising are, therefore, key elements of program design for voluntary mechanisms. 
A more recent review (Khanna and Damon, 1999) suggests that the program did achieve better reductions than would have been achieved under standard regulatory mechanisms but that it worked, in part, because there was a threat of mandatory regulation and there were cost-sharing subsidies. They also noted that participating firms were more likely to have older equipment (due for replacement), be members of industry associations, have a large volume of releases and be subject to public disclosure of their releases. They concluded that "rational economic self-interest" was the key motivator in participation.

\subsection{US EPA Project $X L$}

The US EPA Project XL is a pilot project that stands for eXcellence and Leadership. It's intent (US EPA 2000) is for EPA to partner with state and local governments and businesses and federal facilities to develop innovative strategies to test better or more cost-effective ways of achieving environmental protection. The project has eight selection criteria:

- Produce superior environmental results beyond those that would have been achieved under current and reasonably anticipated future regulations or policies;

- Produce benefits...that serve as an incentive to both project sponsors and regulators.

- Have support by stakeholders.

- Achieve innovation/pollution prevention.

- Produce lessons/data that are transferable to other facilities.

- Demonstrate feasibility.

- Establish accountability through monitoring, reporting and evaluations; and

- Avoid shifting the risk burden.

The first of these criteria has proven extremely problematic to define.

To further evaluate Project XL, we interviewed Weyerhaeuser staff from their Flint River Division in Georgia with the assistance of Guy Wilson of Weyerhaeuser's Alberta Division in Grande Prairie. The Flint River XL Project was the third one approved from a current total of about 16 EPA agreements. Another 19 are being negotiated at this time (March 2000). All of these are pilot projects to test the application of the program. The XL Flint River agreement was signed in January 1997 and has a 15-year life.

The agreement calls for Weyerhaeuser to reduce a number of its waste streams and achieve efficiencies in processes that reduce costs of production and minimize effects on the environment. The changes are phased over time, with the more easily attainable ones being done first and the more capital intensive ones coming later. Some of the improvements are ones that the company had been considering implementing on their own. Specific examples of performance deliverables include: a plant site EMS; reductions of wood waste; reductions in total water use; reductions in BOD, TSS and bleach 
plant colour; upgraded odour control systems; condensate removal and burning; an EMS for their timber harvesting operations; energy conservation measures; and a reduction in overall HAPS emissions.

The facility gained public acknowledgement, reporting flexibility, freedom to implement onsite process changes, and the ability to negotiate how they would meet their HAPS control goals. Over the life of the agreement the company anticipates a cost saving of more than $\$ 8$ million.

\subsection{US EPA Innovations}

We have included a rather detailed review of a US EPA report (US EPA 1999) that trumpets its own future actions because it gives a picture of the future direction of the federal US environmental regulator. This is not, however, a review of the programs discussed.

The US EPA, as part of its actions within the Reinventing Government program are building on the experience of some of their previous and existing programs and are initiating a number of actions to improve regulatory performance. This report (US EPA 1999) is focussed on existing and future programs and activities, many of which have not been tested but are, presumably, based on the EPAs own experience as well as those of the Innovations Task Force. The report details ten key actions:

1. Use incentives and voluntary partnerships more wisely to encourage better environmental performance. Under this action they propose to evaluate ongoing pilots and existing incentive programs to look for voluntary partnership approaches with state governments, aboriginal governments, industry and ENGOs. They indicate that one of the tasks will be to remove existing barriers, but they do not indicate what the barriers are.

2. Promote the Use of environmental management systems (EMS). The actions here include encouraging the use of EMSs and evaluating the components of successful EMSs.

3. Develop a "performance track" to motivate and reward top environmental performance. This includes programs such as XL (see above) and the report notes that it is not without controversy. The initial goal is to find ways to define and measure environmental excellence.

4. Support a network of public and private organizations that provide assistance on environmental compliance. Their intent here is to sell, as a wholesaler, compliance assistance tools and information. They justify this because "many regulated groups... are wary of seeking help from EPA". 
5. Deliver compliance assistance information for new "economically significant" rules when and where it's needed. The goal is to provide this information within 90 days of the issuance of new rules, i.e., before they take effect. This would allow facility managers to better incorporate activities to meet the new rules into their management practices. An "'economically significant" rule is one that is expected to have an impact of $\$ 100$ million or more.

6. Combine compliance assistance, incentives, monitoring, and enforcement in order to implement environmental laws in a more strategic manner. The goal here is to make better use of limited resources. The focus is generally on compliance assistance first, then incentives (such as penalty relief for firms that self-audit, quickly disclose and correct problems). Monitoring and enforcement are the sticks to encourage companies to participate.

7. Develop more flexible air permitting policies for protecting the environment. This is based on programs such as XL and Pollution Prevention in Permitting Project (P4). This is a future action based on audits of existing systems and appears to be primarily an information dissemination program.

8. Speed up review and issuance of NPDES (water discharge) permits. A pilot program, using the National Pollution Discharge Elimination System will be tested. The goal is to streamline permitting by encouraging applicants to submit draft permit limits and conditions to the regulatory agency. They also indicate that they will encourage public involvement in the permitting process. The later does not seem to include having applicants discuss the limits and conditions with the public prior to submitting them for review by the regulator.

9. Build leadership capacity in communities to participate in local environmental problem solving. The intent of this is to facilitate local dialogue on environmental issues and provide technical assistance and information. As with Action 10, below, this is in an area where the EPA has no regulatory role.

10. Provide "smart growth" support to other orders of government to help them find local solutions to liveability issues. This is an information out action.

As part of their reinvention review, the Innovations Task Force sought comments from business and community representatives, state government and EPA staff. The mechanisms of this outreach are not detailed in the report. The main messages that they received were:

- Encourage stewardship 
- Recognize top performers. The criteria for defining top performance should be multi-media and include measures such as public disclosure, public involvement, how well particular environmental problems are addressed, product stewardship and mentoring other companies. A "ladder" approach, recognizing different performance levels was suggested.

- Incentives. Instruments such as fewer inspections, increased flexibility, reduced reporting and monitoring and tax credits were suggested as possible incentives, along with formal recognition.

- Environmental Management Systems. One option to encourage their use would be to have insurers, bond raters and others use EMSs as part of their evaluation of a company.

- Integrating environmental and business decisions. This is one goal of an EMS but other mechanisms, such as life-cycle analysis and full cost accounting could be used.

- More voluntary programs

- Market based or economic incentives. The main example here is effluent trading.

- Improved regulations. Suggestions included plain language approvals, performance based regulations, sector based rule making and more openness during rule making.

- Permitting, monitoring and reporting reforms. Recommendations included items such as consolidating monitoring and reporting and allowing it to be done electronically, one-stop permitting and sector based permits.

These comments are indicative of the kinds of initiatives being implemented elsewhere. There were also a number of suggestions around compliance assistance and information dissemination.

Overall, the approach suggested in the report seems to focus on the compliance assistance/information aspects. The actions are primarily nonregulatory and are directed as much at the operations and actions of the EPA as at the regulated parties. Only 1, 2, 3 and, possibly, 7 and 8 have any alternative or innovative regulatory mechanisms associated with them. Many of the actions, when reviewed in detail, appear to be extremely bureaucratic in nature and might result in a need for increased resources for the EPA.

\subsection{Multi-State Working Group}

The Multi-State Working Group is a consortium of federal and 15 state agencies along with non-governmental organizations, industry representatives and academia. It's role is to examine the policy implications 
of environmental management systems, especially ISO 14001 (MSWG 2000a). They meet quarterly to discuss relevant issues and have sponsored workshops and a research summit. The current focus is to compile a national database (MSWG 2000b), using industry information from 80 pilot participants, that will be used to study how EMSs affect environmental performance.

\subsection{Wisconsin's Green Tier Concept}

The Green Tier regulatory concept is a proposed voluntary program. It would allow both regulated and unregulated organizations to do "good works" that are beyond good compliance (Wisconsin 2000). This program is still in the exploratory stages and will have a period of input and discussion to determine new policy. They do have four key principles:

- The basic command and control system will remain, along with its compliance mechanisms, for those that do not wish to join or are not qualified to join the Green Tier program.

- The Green Tier will be governed by contract law. The contracts will include sanctions for any party, including government, that fails to meet the contracts' terms. Incentives such as regulatory flexibility and tax benefits are seen as major enticements to participate.

- The program goal is "civic environmentalism". This involves being at or beyond compliance, giving attention to priority unregulated problems and creating "environmental gain" that produces value for the community.

- EMSs will be used to establish goals, track progress, report results, and produce improved performance over time. Incentives may be used to encourage participants to report results to the community.

This is not a statutory program and will require legislative change to enable its implementation.

\subsection{Oregon's Green Permits}

The Green Permits program was enacted in Oregon in 1997. The legislation encourages the regulator to use innovative environmental approaches or strategies to encourage regulated facilities to achieve environmental results that are significantly better than otherwise required. The Department of Environmental Quality is currently exploring an approach based on the use of EMSs and a multi-level system in which greater demonstrated environmental performance is acknowledged with increasing regulatory flexibility (Oregon 2000). The approach is being piloted at four different facilities.

Key principles are:

- Environmental performance is expected to exceed minimum requirements. 
- Measurable goals will be established that should result in real and quantifiable gains. The project may also recognize gains in areas not traditionally covered by regulatory permits, such as riparian habitat.

- Meaningful stakeholder involvement.

- Balance simplicity and certainty with flexibility and innovation in the permits.

The expected benefits include regulatory incentives, public recognition and a partnership approach to environmental management for industry; and involvement opportunities and better understanding of a facility's environmental performance issues for the public. It is anticipated that the program will address a wider range of environmental impacts than those covered by existing regulation, therefore resulting in an enhanced environment.

\subsection{Netherlands - Environmental Covenants}

The Netherlands approach to greenhouse gas emission controls has been to use environmental covenants based on Integrated Environmental Objectives (IEO). As described by De Hoog (1998), it is a two step process. First the federal government works with industry sectors (often associations) to develop a National Environmental Policy Plan (NEPP) which determines the emission reduction targets for each sector. These plans are determined at a very senior level through an intra-sectoral consultative group. The theory is that this process uses peer pressure to bring most companies into line. Once all parties have agreed the negotiated reductions and time frame, a covenant is signed between government and the industry sector. This provides security to both parties and details the terms under which the industry sector will have to implement the IEOs.

The next step is for the individual companies to implement this through a Company Environmental Plan (CEP). The CEP is approved by the authority granting the licence, usually local, and is renewed every four years. If a company's CEP makes enough of a contribution to the IEO then it's licence will be amended (e.g., to permit more internal flexibility). If the company doesn't adhere to its CEP then its licence can be tightened.

Government benefits from this approach through sector wide, rather than company by company negotiations. It is also assumed (de Hoog 1998) that the extent of reductions necessary in the Netherlands could not have been achieved through conventional regulatory methods; the reductions required fundamental changes in production processes. Industry benefits because they can implement measures on their time frame with an understanding of the long-term environmental goals. Before CEPs licences were prescriptive, providing detail on the technology to be used and the government/industry approach was frequently confrontational. With the CEPs, there are facility wide objectives, reliance on company environmental management systems (EMS), and straightforward regulations around reporting environmental performance and 'unusual' events. Licences have been reduced from being 
hundreds and thousands of pages long to a few pages with a few dozen requirements.

The program appears to have been working but the author notes that there were a number of initial problems that took a lot of effort and dialogue to solve. A major factor still to be resolved is the participation of the public and/or ENGOs. Most Netherlands ENGOs subscribe to the potential benefits of the process but would like to see a more transparent and factual dialogue between themselves and industry.

De Hoog (1998) notes six conditions for effective agreements:

- A basic level of regulation including compliance monitoring and enforcement.

- A shared vision of the long-term goals.

- A robust EMS in each participating company

- Government ability to deal with free riders

- Transparent and public monitoring and reporting

- Sufficient public awareness and pressure on industry to improve their environmental performance.

And, in his estimation, the most important element is mutual trust.

\subsection{United Kingdom}

A review of the United Kingdom's greenhouse gas mitigation options (Penman, 1996) found that a number of components were necessary in order to achieve the desired results. First was a need for national consultation, lead by government, who needed to set the basic legislative and fiscal framework. This was achieved through widespread distribution of a discussion paper followed by four major workshops to examine the scope of action for different economic sectors and then a major national conference. The participants determined that a successful program had to have balance through all sectors, flexibility (focus on voluntary measures as much as possible), a coercive element of some sort (fiscal, i.e., taxes were seen as the best approach), information, and incentives (preferably financial). For a targeted program such as greenhouse gas emissions, they also saw a need for a measurable inventory capability and the ability to control incentives and penalties based on external factors. The later was seen as important because previous studies had shown that $\mathrm{CO}_{2}$ emissions (and others) were more strongly correlated to the price of oil than to any voluntary or regulatory efforts to control (Selden et al. 1999). The UK system includes regular monitoring of results and adjustments to their predictive model to further assess the affects of external factors as compared to incentives in achieving changes in greenhouse gas emissions. 


\subsection{Germany - Greenhouse Gas Reduction}

Germany is using "voluntary agreements" (VA) as a mechanism to reduce greenhouse gas emissions. Kabelitz (1998) indicates that the chief reasons for implementing the VA approach in Germany were the belief that regulatory approaches could be a barrier to efficient solutions and a recognition that companies could not bear a greater taxation/charges burden. The approach is for government and industry associations to agree to reduction targets appropriate to each association. The industry associations then work with their members to achieve the targets.

The process has two key components to discourage free riders 2 : monitoring and financial penalties. Annual, detailed, audited monitoring reports are required. These detect companies who are not performing as required and these companies loose their exemption from a $\mathrm{CO}_{2}$ tax. The later is an implied regulatory threat, which could be viewed as coercing participation. The monitoring reports are prepared by an independent institute, which is cost shared by government and industry. An interesting component of this program is that the monitoring reports are submitted to parliament, thus being open to question and becoming part of the public record.

The program achieved $25 \%$ of its reduction target for 2005 between 1990 and 1996. It is unclear whether the remaining $75 \%$ can be achieved through this approach alone as the easy fixes have been implemented and it is becoming incrementally harder to achieve further reductions.

\subsection{Australia - State of Victoria's Environmental Improvement Plans (EIP)}

Wills (no date) discusses the application of the state of Victoria's Environmental Improvement Plans (EIPs) to a petrochemical complex. The plans are strategies, drawn up by a company or group of companies in consultation with Victoria's Environmental Protection Authority and the local community. Basic components of the plans are a commitment to continuous improvement, community right to know and community involvement in monitoring and review of operations. The plans require the formation of community liaison groups that include EPA staff, industry site managers and community members to undertake the monitoring, review and reporting processes.

EIPs have a statutory framework that includes the beneficial uses of the environment to be protected, and the environmental quality objectives and indicators. The intent is to reduce the need for enforcement as well as improve environmental quality. The case study cited is an example of a 'place-based' approach to environmental management. Seven different plants (owned by four companies) in one industrial complex are involved in the EIP,

\footnotetext{
${ }^{2}$ Individual members of industry associations who gain a competitive edge by not participating
} or not participating fully. 
which involves the local community in determining emission levels. In this particular example a local municipal councillor chairs the liaison committee.

Strategic components of an EIP program include an understanding of each party's existing rights and obligations, the ability to measure the cost of alternative strategies to the producer and to the environment, and a mechanism to require monitoring and enforce penalties. This information includes an understanding and appreciation by all members of the values held by each member. The liaison committee also provides a venue for nonmembers to air concerns and complaints. Both the government and industry members are expected to respond.

The review (Wills, nd) notes that different pollution control strategies, within a plan, would be required for different categories of pollution problems. $\mathrm{He}$ characterizes two problems. The first is 'normal operating pollution' - the emission of standard pollutants which most plants are likely to emit and which are well mixed in the receiving media (e.g., greenhouse gases). The second category is system breakdown pollution - the emission of substances which are toxic in nature and which are specific to a particular plant. $\mathrm{He}$ notes that there are more incentives to monitor and regulate individual facilities for this kind of situation, whereas regional or less specific monitoring and regulation may be more appropriate to the first situation.

\subsection{Key Components of Existing Programs}

The goal of most of these programs is twofold: to reduce the cost of compliance and improve environmental performance. In a review paper, Lachman (1997) observes that the current, voluntary approach may have reached the extent of its effectiveness, especially in the US's adversarial, multi-level regulatory milieu. The recommendation from this survey is for a two-track approach that provides preferred treatment, such as streamlined administrative and permitting requirements, easing inspection and enforcement, and providing assistance and/or financial incentives for good performers. The paper also cautions against expecting changes to occur quickly. The traditional command and control system will have to stay in place as the two-track system evolves.

A contrasting opinion (Solsbery and Wiederkehr 1995) proposes that no single policy measure, including regulation, is enough to achieve the desired results. They note that governments are increasingly reluctant to resort to heavy-handed fiscal or regulatory measures on firms that have to compete in global markets. In these circumstances, governments and industries have been looking to innovative approaches including voluntary agreements and economic instruments (emissions trading, differential tax structures). They postulate that the main reasons for using voluntary agreements (with or without significant compulsion) are to increase the involvement of companies in achieving better environmental performance, to increase the motivation of companies and consumers, and to use policy instruments that are better adapted to the economic and competitive context. They indicate that the 
effectiveness of voluntary and innovative mechanisms will depend on their structure, how closely they are monitored, the extent of participation, the control of free riders and the type and strength of regulatory backup.

Barber (1998) provides an assessment of NGO perspectives on voluntary initiatives. He indicates a need for greater transparency, independent verification of results, inclusiveness for all parties and complementary use of an enabling regulatory framework. NGOs most prominent concerns are the lack of independence or verification in monitoring and reporting (government is not seen by many as sufficiently independent), green washing - a focus on public perception rather than meaningful change, and the disservice done to responsible companies by free-riders.

Segerson and Miceli (1998) in testing whether voluntary agreements were likely to protect the environment found that it depends on the allocation of bargaining power, the size of the potential regulatory threat and the social cost of the funds to implement. Voluntary agreements produce the best environmental results and exceed what could be achieved by regulations alone when the regulator has all of the bargaining power and a strong carrot/stick (such as exemption from mandatory compliance). If the regulator isn't in that strong a position then adding some form of subsidy (in-kind services or money) can also achieved enhanced performance. If the ind ustry holds the stronger bargaining position (usually through political means) then environmental abatement is less with voluntary agreements than would have been achieved by existing regulatory means.

\section{Summary}

In summary, the literature review indicated that there were two key factors that were necessary for any innovative program to be successful and highlighted a number of related key program components. The key factors are a willingness to participate by all parties (industry, government, ENGOs/public) and an element of trust among the participating parties.

The key components of a program include:

- Shared vision of long-term environmental goals

- Broad information base

- Reduced costs for compliance and for regulator administration

- Transparency through all aspects of the program

- Regulatory backstop - both compliance measures and enforcement

- Publicity and consumer awareness

- Binding agreements

- Regional implementation

- Facility/site based and/or place-based (i.e., more than one facility in a discrete location).

- Include an environmental management system 
- Performance measurement that is regular, open and publicly distributed

- Independent auditing - not mandatory but improves credibility.

- Mechanisms to control free-riders

- Program designed so that it doesn't result in increases in non-target pollutants or affect other programs.

- Resources to support public/ENGO participation 


\subsection{Designing an Alberta Approach to Alternative/lnnovative Approvals (AIA)}

\subsection{Key Features of an Innovative Approach}

In questions 13-21 we evaluated what the key features and purposes of any new innovative and alternative regulatory approach might be. These questions (see Appendix A) addressed the key elements, public perceptions \& participation, benefits to the parties, implementation mechanisms any possible entry requirements for an AIA program. Table A tabulates the responses from the three groups of interviewees. Overall there is good concurrence across the group responses.

Analysis of the key features desired by ENGO, industry and government reveals that there is support for adoption of new and innovative regulatory approaches. Such a system would address a wider range of environmental impacts, encourage a pollution prevention approach, emphasize continual improvement, be based on sustainable business practices including environmental management systems, and would result in long term reductions in emissions to the environment. Such a system could also be a powerful tool for the implementation of a broad range of pollution prevention (P2) principles and policies.

Ideally, a properly designed, system would set results-oriented pollution minimization goals with government and public participation that would lead to cost savings, operation efficiencies (via EMS) and foster a renewed partnership with industry and the public. This partnership climate would lead to the recognition of facilities for their enhanced environmental protection.

Environmental performance measures would be mutually established and tracked on a facility basis. This would lead to a better system for the distribution of information, enhanced public stakeholder knowledge of impacts and an improved database for future decision making. 


\begin{tabular}{|c|c|c|c|}
\hline \multicolumn{4}{|c|}{ Table A Assessment of Key Features of new Innovative Regulatory Approach } \\
\hline Subject/Issue & Industry Response & ENGO Response & Gov't. Response \\
\hline Public perception & Vital to success & Essential component & $\begin{array}{l}\text { Needs fundamental } \\
\text { accountability in } \\
\text { govt and public }\end{array}$ \\
\hline $\begin{array}{l}\text { Incentives for good } \\
\text { performers }\end{array}$ & Attractive feature & $\begin{array}{l}\text { Useful concept with } \\
\text { guarantees } \\
\text { Rewards should be } \\
\text { commensurate with } \\
\text { performance } \\
\text { Remove benefit for } \\
\text { failure to perform }\end{array}$ & $\begin{array}{l}\text { Removal from } \\
\text { program for poor } \\
\text { performance }\end{array}$ \\
\hline $\begin{array}{l}\text { Relief from } \\
\text { ratchetting down }\end{array}$ & Very important & $\begin{array}{l}\text { Still need continuous } \\
\text { improvement in } \\
\text { many cases }\end{array}$ & $\begin{array}{l}\text { Long-term } \\
\text { improvement } \\
\text { continues to be an } \\
\text { objective }\end{array}$ \\
\hline $\begin{array}{l}\text { Tradeoffs within the } \\
\text { present system }\end{array}$ & $\begin{array}{l}\text { Bubble permits would } \\
\text { help (flexibility) } \\
\text { Streamlined } \\
\text { approvals and } \\
\text { amendments } \\
\text { desirable }\end{array}$ & $\begin{array}{l}\text { Verification or audits } \\
\text { needed } \\
\text { Don't weaken present } \\
\text { system }\end{array}$ & $\begin{array}{l}\text { Requires clearly } \\
\text { definable goals and } \\
\text { industry-gov't. } \\
\text { verification } \\
\text { Don't weaken } \\
\text { present system } \\
\text { Appeal Mechanism }\end{array}$ \\
\hline $\begin{array}{l}\text { High cost to industry } \\
\text { for low but } \\
\text { regulated } \\
\text { environmental } \\
\text { gains }\end{array}$ & $\begin{array}{l}\text { Relevant for some } \\
\text { sectors-linked to } \\
\text { cost effectiveness }\end{array}$ & & \\
\hline $\begin{array}{l}\text { Flexibility within } \\
\text { approvals for a } \\
\text { broader range of } \\
\text { issues and } \\
\text { opportunities }\end{array}$ & $\begin{array}{l}\text { Prepared to ensure } \\
\text { lower impacts for } \\
\text { flexibility } \\
\text { Waste reduction via } \\
\text { reuse by others }\end{array}$ & $\begin{array}{l}\text { Broader range of } \\
\text { benefits endorsed } \\
\text { Desire to handle } \\
\text { cumulative effects } \\
\text { expressed }\end{array}$ & $\begin{array}{l}\text { Flexibility acceptable } \\
\text { for measurable } \\
\text { gains for } \\
\text { environment }\end{array}$ \\
\hline $\begin{array}{l}\text { Cost and } \\
\text { effectiveness of } \\
\text { regulatory system }\end{array}$ & $\begin{array}{l}\text { Desire to achieve } \\
\text { most cost effective } \\
\text { protection }\end{array}$ & & \\
\hline $\begin{array}{l}\text { Public confidence } \\
\text { and acceptability }\end{array}$ & Vital to success & $\begin{array}{l}\text { Vital to success } \\
\text { Enshrine public } \\
\text { rights }\end{array}$ & $\begin{array}{l}\text { Vital feature for } \\
\text { success }\end{array}$ \\
\hline Transparency & $\begin{array}{l}\text { Key for public } \\
\text { acceptability }\end{array}$ & $\begin{array}{l}\text { Key for stakeholder } \\
\text { involvement }\end{array}$ & $\begin{array}{l}\text { Key to public } \\
\text { involvement }\end{array}$ \\
\hline Others & $\begin{array}{l}\text { Federal-Prov. gov't. } \\
\text { co-ordination } \\
\text { Use existing system } \\
\text { such as ISO } 14000 \\
\text { Improve data } \\
\text { reporting }\end{array}$ & $\begin{array}{l}\text { Don't reduce } \\
\text { monitoring }\end{array}$ & $\begin{array}{l}\text { Need to define } \\
\text { failure to meet } \\
\text { goals: i.e. small vs. } \\
\text { large deficiencies }\end{array}$ \\
\hline
\end{tabular}




\subsection{Core Principles for an Alberta Alternative/Innovating Approval System}

A review of the interviews and the assessment of the current regulatory system, coupled with experience in other jurisdictions and discussions with the SAC provided the basis for the following core principles.

Any new system should include:

- Participation by government, industry and ENGOs/public to achieve win-win-win solutions

- Open and transparent operations and decision making,

- Performance which exceeds present regulatory requirements is the baseline entry requirement for the program,

- The existing regulatory system should not be weakened by new approach, but strengthened, augmented, and refocused,

- Significant measurable environmental performance goals will be set and attained,

- Meaningful stakeholder involvement,

- Modifications to the present regulatory system should allow increased flexibility and innovation, in exchange for significant environmental benefits,

- Benefits should accrue to industry, government and the environment, these should be based on a renewed partnership embracing EMS,

- To the extent possible, use existing systems to speed implementation,

- A mechanism to expel free riders.

\subsection{Important Trade-Offs And Limitations}

Within each sector there was agreement that progress could be made and that there were key elements that would be integral for success.

Based on the interview results, industry is prepared to commit to measurable performance targets to lower pollution to the environment in exchange for flexibility in the way these goals are met. In some cases this may require the waiving of currently constraining or proscriptive license clauses which specify equipment or process to be used. In this way environmental enhancement could occur with further ratchetting down of compliance limits. An additional incentive to industry would be recognition of exemplary environmental performance. Streamlining of regulatory processes, including a better reporting system, were acknowledged benefits recognized by all groups.

The environmental groups (ENGOs) could support a new system if it was either entrenched in regulations or had a strong regulatory backstop and featured prominent stakeholder participation. Also very important to this group was the ability to verify or audit both progress on pollution prevention and reductions in emissions since this was viewed as a major deficiency of many of the existing voluntary systems.

The leaders in government recognized the utility of a new system that would have the strengths of the present compliance-based system, and the added incentives of rewards for exemplary performance. However, with a long history in which all compliant facilities are treated equally, government will 
be demanding as to the performance measures required and vigilant on attainment. Since the public service will ultimately have to administer the system, members cautioned that fair rules would have to be developed to deal with both major and minor failures to perform.

All groups were clearly unified that any new system would have to have public confidence and public credibility as core requirements.

Finally, there was suspicion that reducing monitoring requirements could weaken the information base, although all groups supported the idea of improving data reporting and access systems. Recent developments in computer bulletin boards, email and the World Wide Web should be utilized to the extent possible.

\subsection{Benefits of Alternative \& Innovative Approaches}

Within the scope of activities and goals identified for the project, a series of potential benefits for industry, government and the environment were developed and tested with the Study Advisory Committee in March 2000. The origin of these potential benefits came from the interviews and the analysis of programs in the United States and Europe. This same process was used to determine which elements of a possible program would not be supported and should be eliminated from further consideration.

\section{Benefits to the Environment}

- Reduced emissions from the facility

- Improvements over a broader range of impacts

- Potential redirection of present waste streams

\section{Benefits to Industry}

- Regulatory incentives (Bubble licensing, single point of contact, etc)

- Recognition of exemplary performance

- Partnership approach to EMS

- Public recognition for environmental performance

- Flexibility beyond regulatory command \& control

- Waiver of some constraining conditions

- Streamlined permitting and approvals process

\section{Benefits to Government}

- Adds motivation/incentives to traditional management tools

- Benefits of EMS codified in agreements

- Reduced administration coupled with a broader range of potential environmental benefits

- Enhances environmental performance well beyond compliance limits

- Potential for cost recovery of administration efforts

\section{Benefits to the Public and ENGOs}

- Provides a on-going role in industry consultation (versus the current 10 year cycle) 
- Benefits of better, well integrated performance based information

- Constructive opportunity to discuss companies performance and corporate environmental policies within EMS structure

- Future performance commitments linked to regulatory license requirements through agreements 


\subsection{A Proposed Alternative \& Innovative Regulatory Model for Alberta.}

The following system utilizes the results of the interviews of all participants and their requirements. The model, which is outlined in detail in Table B, is a harmonious blend of the key features and drivers required by all groups. It has not been necessary to trade off the expectations of any one group. The system is facility based, that is it deals only with the performance of a single facility; permit trading is specifically prohibited, as is the transfer of benefits from one facility to another.

The system is based on company or facility environmental management systems, such as ISO 14001, being implemented by industry; this includes the establishment of beyond-regulatory performance measures being set and evaluated with stakeholder participation. Achievement time frames, verification and audits are included to ensure public and government confidence.

Entry into the AIA system would be voluntary, but once in, companies would be required by their new license conditions to meet the established performance measures within the defined time frames. The process would be fully transparent and constitute a renewed partnership among government, industry and the public. All participants would commit to performing better than existing regulatory compliance, using continuous improvement pollution prevention principles, and defining targets for performance measures.

To deal with the learning and experience required to develop and implement an EMS, and the need to adjust a company's status if goals are not met, we have proposed a three tier system with increasing responsibilities and rewards.

Tier 1 is essentially an entry level into the program which would be available only for one renewal period, while Tier 2 and 3 require greater levels of commitment in EMS development and auditing of emissions as well as improved delivery of desired outcomes. The scope of Tier 2 and 3 benefits to the environment is also broader. Tier 3 would be reserved for only the few highest performing companies, those that are outstanding leaders in their sector with comprehensive management of wastes, processes and by-products from cradle to grave.

As described, companies would evaluate the program's entry requirements and if interested would approach government with a statement of interest, possibly requesting a meeting to discuss their facilities past and future performance. At this point government would provide notice to other interested parties, such as ENGOs, who would have the option of joining the discussions.

The scope of the planned performance targets would be determined by the facility's operations and by local issues that are pertinent to the facility's use 
of resources and its emissions. Planning horizons for the length of the agreement should be sufficiently long to allow corporate planning for capital expenditures and to properly evaluate the attainment of performance measures; five, ten and fifteen years would seem reasonable.

A series of rules and worksheets should be developed to implement the program, and these could be tested during a pilot phase across several industrial sectors. Their purpose would be to provide clear expectations to those both contemplating joining and those within the program. Government, industry and ENGOs should participate fully in the development of these materials so that they have complete confidence in the program when it reaches full implementation.

\subsection{Roles \& Responsibilities Within an Al Approval Program}

Within the proposed system industry takes the lead in applying to the program once they have developed their EMS or committed internally to do so. This is consistent with the voluntary nature for entry into the program. The facility management will submit the EMS documents and a report outlining past performance and relate this to the entry criteria for the program.

Once this step has been taken, the tripartite nature (government, ENGO/public, industry) of the program is engaged by government. Transparency is a prime requirement of the subsequent steps with full ENGO/public, industry and government knowledge of future events.

Based on the EMS and discussions among industry, government and ENGO/public interests, a series of possible environmental benefits are identified and these are relayed to all parties to begin the negotiations leading to the establishment of performance measures. These are to be significant gains for environmental management and must be measurable with clearly defined time frames for their attainment. 


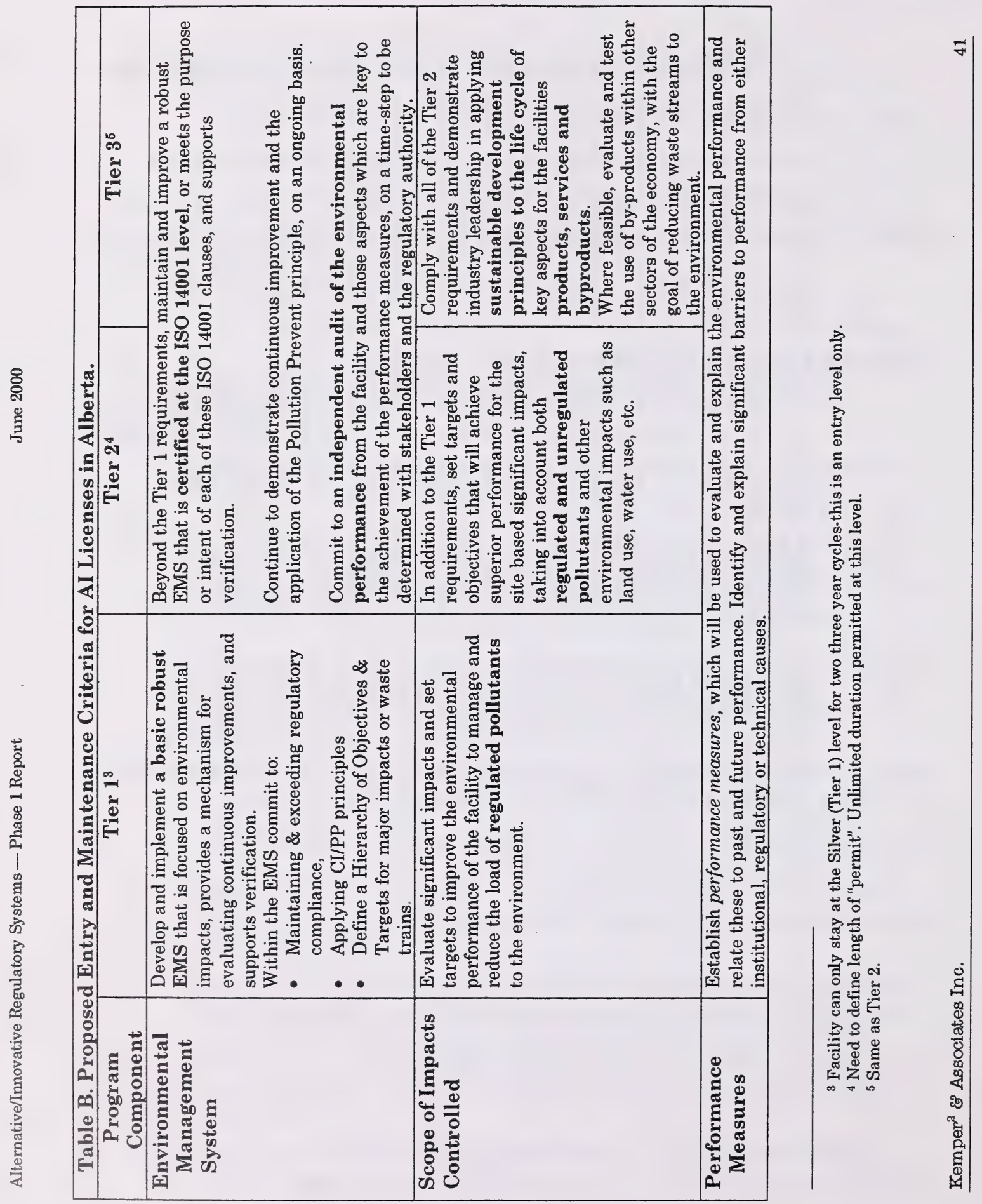




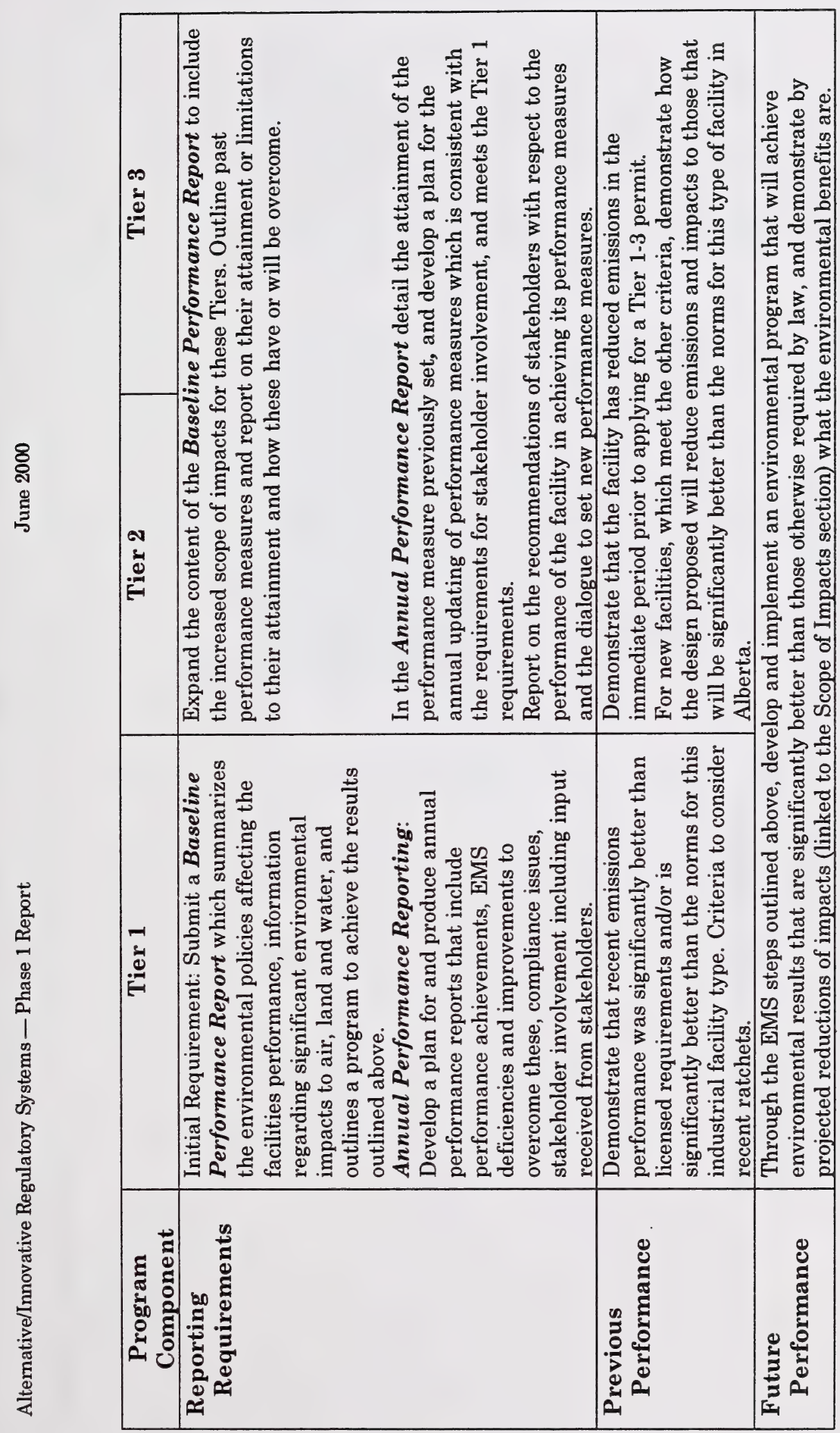




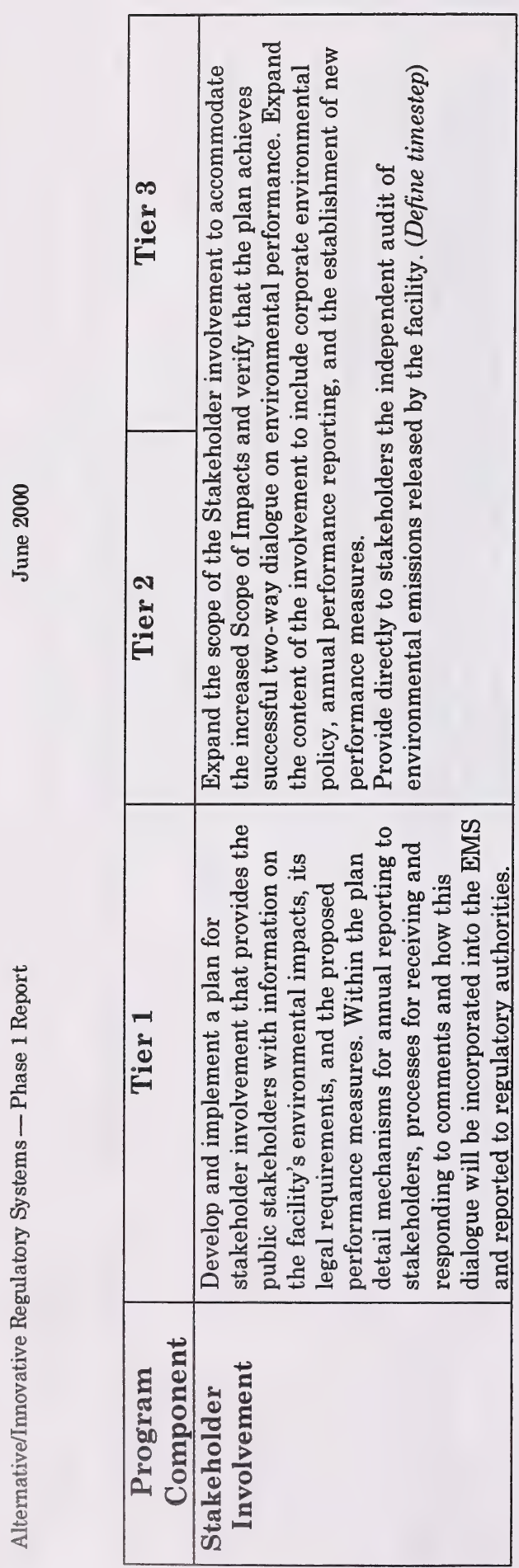


The lead role in administering the application falls to government, likely to a team leader who acts as a single point of contact for the AI approval.

Government provides technical assistance and interpretation to the review team, which may involve members of ENGO groups or local residents. Government assesses the application, judges the merits of the various positions and has the final responsibility to accept or reject the application. The approval is then prepared using some of the process and application documents as back up. In summary:

- Industry: Prepares EMS and AI approval application, suggests performance goals, identifies regulatory offsets, commits to and defines annual reporting, stakeholder participation.

- Government: Manages Evaluation Teams, helps set performance goals, evaluates the need for offsets, other administrative aspects, and revises the approval for the facility.

- ENGOs/public: Participates in evaluation of application with industry and government, provides evaluation of goals attainment, annual reports, and recommends new performance measures for Tier $2 \& 3$.

Under this system, all three parties would share responsibility for ongoing monitoring of the agreement, performance assessments, etc. throughout the term of the agreement. 


\subsection{Bibliography}

ARET Secretariat. 1996. Lessons learned from ARET: A qualitative survey of perceptions of stakeholders. Available from the Secretariat, Ottawa. 31pp.

Arora, S. and T.N. Cason. 1995. An experiment in voluntary environmental regulation: participation in EPAs $33 / 50$ program. J. Environ. Econ. Manag. 28: 271-286.

Arora, S. and T.N. Cason. 1996. Why do firms volunteer to exceed environmental regulations? Understanding participation in EPA's 33/50 Program. Land Econ. 72(4): 413-432.

Barber, J. 1998. Responsible action or public relations? NGO perspectives on voluntary initiatives. UNEP Industry and Environ. Jan-Jun 1998: 19-22.

Beaulieu, Patricia 1997. The VCR doesn't work. Alternatives Journal 23(3): 4.

CCPA. 2000a. Canadian Chemical Producers Association home page http://www.ccpa.ca/english Accessed March 7, 2000.

CCPA. 2000b. Responsible Care®: The picture is getting brighter. 1999 Annual Report. http://www.ccpa.ca/english/library/RepDocsEN/RC99EN.pdf Accessed March 9, 2000.

CEFIG. 2000. Information from their web page http://www.cefic.org/activities/hse/rcl. Accessed March 23, 2000.

De Hoog, M. 1998. Environmental agreements in the Netherlands: sharing the responsibility for sustainable industrial development. UNEP Industry and Environ. Jan-June 1998: 27-30

Environment Canada. 2000. ARET home page at http://www.ec.gc.ca/aret/homee.html. Accessed March 7, 2000.

ICCA. 2000. Responsible Care® Annual Report 1998. Viewed at http://www.icca-chem.org/rcreport98/. Accessed March 23, 2000.

Kabelitz, Klaus. 1998. The role of voluntary agreements in Germany. UNEP Industry and Environment, Jan-June: 44-48.

Khanna, M. and L.A. Damon. 1999. EPA's voluntary 33/50 Program: Impact on toxic releases and economic performance of firms. J. Envir. Econ. Manag. 37: 1-25. 
Lachman, B. 1997. Beyond Command and Control. An Evolution is occurring in State and Local Government Environmental Activities. Paper presented at Air and Waste Management Association 90 th Annual Meeting and Exhibition. Reprints: National Defence Research Institute and Critical Technologies Institute. Rand, Santa Monica, CA.

Lever, Hugo. 1998. Responsible Care® in action. UNEP Industry and Environment, Jan-June: 49-53.

Lukasik, Lynda. 1998. Dofasco deal cuts pollution and controls. Alternatives Journal 24 (2): 8-9.

Multi-State Working Group. 2000a. MSWG's home page. http://www.dep.state.pa.us/dep/deputate/pollprev/mswg/mswg.htm Accessed June 2, 2000.

Multi-State Working Group. 2000b. MSWG's program page. http://www.dep.state.pa.us/dep/deputate/pollprev/mswg/research.htm. Accessed June 2, 2000.

Oregon, Department of Environmental Quality. 1999. Green Permits information page http://www.deq.state.or.us/od/green\%20permits\%20\&\%20EMSI/greenpermits htm Accessed March 7, 2000.

O'Toole, L.J., C. Yu, J. Cooley, G. Cowie, S. Crow, T. DeMeo, and S. Hebert. 1997. Reducing toxic chemical releases and transfers: explaining outcomes for a voluntary program. Policy Studies Journal 25(1): 11-26.

Penman, James. 1996. The United Kingdom's assessment of greenhouse gas mitigation options. Environ. Manag. 20. Suppl 1: S75-S81.

Segerson, K. and T.J. Miceli. 1998. Voluntary environmental agreements: good or bad new for environmental protection. J. Environ. Econ. Manag. 36: 109-130.

Selden, T.M., A.S. Forrest, and J.E. Lockhart. 1999. Analyzing reductions in US air pollution emissions: 1970-1990. Land Econ. 75:1-21.

Solsbery, Lee and Peter Wiederkehr. 1995. Voluntary approaches for energyrelated $\mathrm{CO}_{2}$ abatement. The OCED Observer 196: 41-45.

US EPA. 1999. Aiming for Excellence: Actions to Encourage Stewardship and Accelerate Environmental Progress. Report of the EPA Innovations Task Force. EPA 100-R-99-006. 68 pp.

US EPA. 2000. Project XL web page. http://www.epa.gov/projectxl/file2.htm Accessed March 9, 2000. 
Voluntary Challenge Registry. 2000. http://www.vcr-mvr.ca/home e.cfm Accessed March 7, 2000.

Wills, I. no date. Information exchange in pollution regulation. $15 \mathrm{pp}$.

Wisconsin Department of Natural Resources. 2000. Green Tier home page http://www.dnr.state.wi.us/org/caer/cea/reinvention/green tier Access June 2, 2000. 


\section{Appendix A. Interview Questions}

\section{Interview Questions}

The following is an outline of the interview questions, which will take 60 to 90 minutes to discuss. We would appreciate your consideration of them prior to our meeting. Not all questions will apply to all groups being interviewed.

\section{Current Regulatory System}

The following questions relate to the current regulatory system and your assessment of its efficacy.

\section{General Questions}

1. Generally, do approvals focus on the key environmental issues?

2. Does the current system achieve the objectives of environmental protection and pollution control?

3. Is the system cost effective for obtaining an approval and for maintaining one?

4. Do you consider the current approval and monitoring reasonable and appropriate?

\section{Sector Specific Questions}

We would appreciate specific examples, where possible, in discussing these questions. If you represent an industry group or are aware of more than one approval situation, you could consider a typical and an exemplary or problematic case.

5. Within the context of the existing approvals, we would like your comments with reference to the following:
a) Type and age of industry/business.
b) Duration of typical approval - impact on business/operations.
c) Do current approvals deal with air, water or land impacts?
d) Approval renewal cycle
e) Do approvals include all major pollutants (chemicals of concern) or activities? Which chemicals or activities are omitted?
A) Are current approvals based on performance measures or operational
criteria? Does current approval specify total emissions or individual
stack or end-of-pipe (point) limits? Is there any flexibility permitted?
g) What is the current approval emission period - annual, monthly, daily, hourly?
h) Are federal approvals required for your business or sector?

6. What are the overall pros and cons of the current system? 
7. Characterize, in general, the type of emissions or activity authorized in your approval and link these to current provincial or national issues, such as:

a) Toxicity/Risk

b) Trend in emissions over recent decades

- Total volume

- Volume related to production (efficiency)

c) Environmental certification/public concerns

8. Does any part of your association membership perform well below their approval limits? If so:

a) What are the benefits of performing below the approval limit?

- Allowance for upsets?

- Reductions in monitoring effort?

b) Is there any disbenefit?

- High treatment costs?

- Reduction of allowable emissions at approval renewal?

\section{Innovative/Alternative Approaches}

The following questions focus on I/A approaches. We are interested in your direct experience, if any, as well as information you have from others who have participated in I/A systems, and your ideas and your suggestions.

Experience with InnovativelAlternative Approaches in Alberta or Elsewhere

9. Has any segment of your industrial group participated in Innovative or Alternative approaches?

a) Where?

b) For what period of time?

c) What types of emissions or activities were involved?

d) What was the goal?

- Reduce emissions

- Internal recycling or marketing

- Internally or externally motivated or driven.

10. Was the I/A Approach successful/unsuccessful, what were the benefits/disbenefits?

11. For any existing or past I/A experiences, how important to your group were the following elements:

a) Corporate acceptability/image

b) Cost

c) Market factors

d) Trade equivalency - free trade legislation

e) Comparative cost in other jurisdictions

f) Relationship to regulations

g) Financing certainty 

h) Public acceptability

12. For these I/A approaches, how were the following aspects dealt with?
a) Verification of environmental outcomes / results
b) Accountability for achieving the environmental objectives
c) Communication with stakeholders and the public
d) Involvement/consultation with community and stakeholders
e) Relationship to regulations

\section{Key Elements of InnovativelAlternative Approaches}

13. In any future blending of existing approvals and voluntary approaches, several aspects will emerge as key drivers. We would like to discuss the following, plus any new aspects which you would like to add:
a) Public perception of your sector/company for those that are not meeting standards (.carrot and stick approach)
c) The tendency for regulators to tighten approval limits when industry consistently does better than required under existing approvals
b) An incentive for good performers to do better and a control mechanism
d) Tradeoffs within the present system
e) The high cost to industry for low but regulated environmental gains when alternative actions outside an approval may yield better results
f) Flexibility within approvals and among a broader range of issues and opportunities
g) Cost and effectiveness of regulatory system
h) The need for headspace (exceedance protection)
i) Cost and effectiveness in achieving environmental protection/enhancement
j) Public confidence

14. Public acceptability will likely be an important aspect of any change from the current system to an I/A approach.
a) What is the typical role of the public in your group's approval process, and also in your day to day operations?
b) What are the strengths or weaknesses (if any) of the process?
c) How would I/A approaches affect this?

15. If modifications are to be made to the present approval system there should be readily identifiable benefits to industry, government, and the public. What are your views on some possible win/win/win scenarios? (A potential list is appended as Table 1.)
a) Faster approval decisions
b) Responses to changing technology
c) Cost reductions to industry or government
d) More certainty (specify)
e) Reduction in emissions
f) Others? 
16. In your view, which implementation tools would be preferable; is this selection based on direct experience or a specific example of which you are aware?

a) Voluntary Initiative

b) MOU for example between the regulator, industry (and stakeholders)

c) Legal agreements

d) Legislative/regulatory changes

e) More flexible approval conditions that focus on the environmental outcome.

17. Are there specific inter-provincial or international trade or harmonization requirements, which you believe might support or hinder development of $\mathrm{A} / \mathrm{I}$ approaches?

18. Considering that the outcome sought by Alberta Environment is protecting the environment through a reduction of total emissions/disturbance to the environment, comment of the significance of each or any of the following as evaluative criteria upon which to measure program success.

a) Absolute emission/disturbance reduction

b) Emissions per unit of production

c) Net cost effectiveness (the implications of diminishing returns?)

d) Public confidence

e) Verification

- Accountability

- Public involvement

- Communication

f) Environmental costs

- To taxpayer

- To industry

19. Recognizing that there would be entry conditions necessary to be part of any modified approval system, comment on these possible criteria for entering into a I/A program:

a) Credible track record

b) Public consultation mechanism in place

c) Transparency of environmental decision making

d) Capacity to act in emergencies

e) Senior management support

f) Others

20. Are there specific existing or past examples within your sector, which illustrate good or poor examples of I/A approaches? What can we learn from these?

21. Do you have any other comments or observations? 


\section{Summary}

If time permits, a discussion of possible new approaches, based on the information derived from the above questions would be useful. If you would like to provide written comments they would also be welcome. 
Table 1

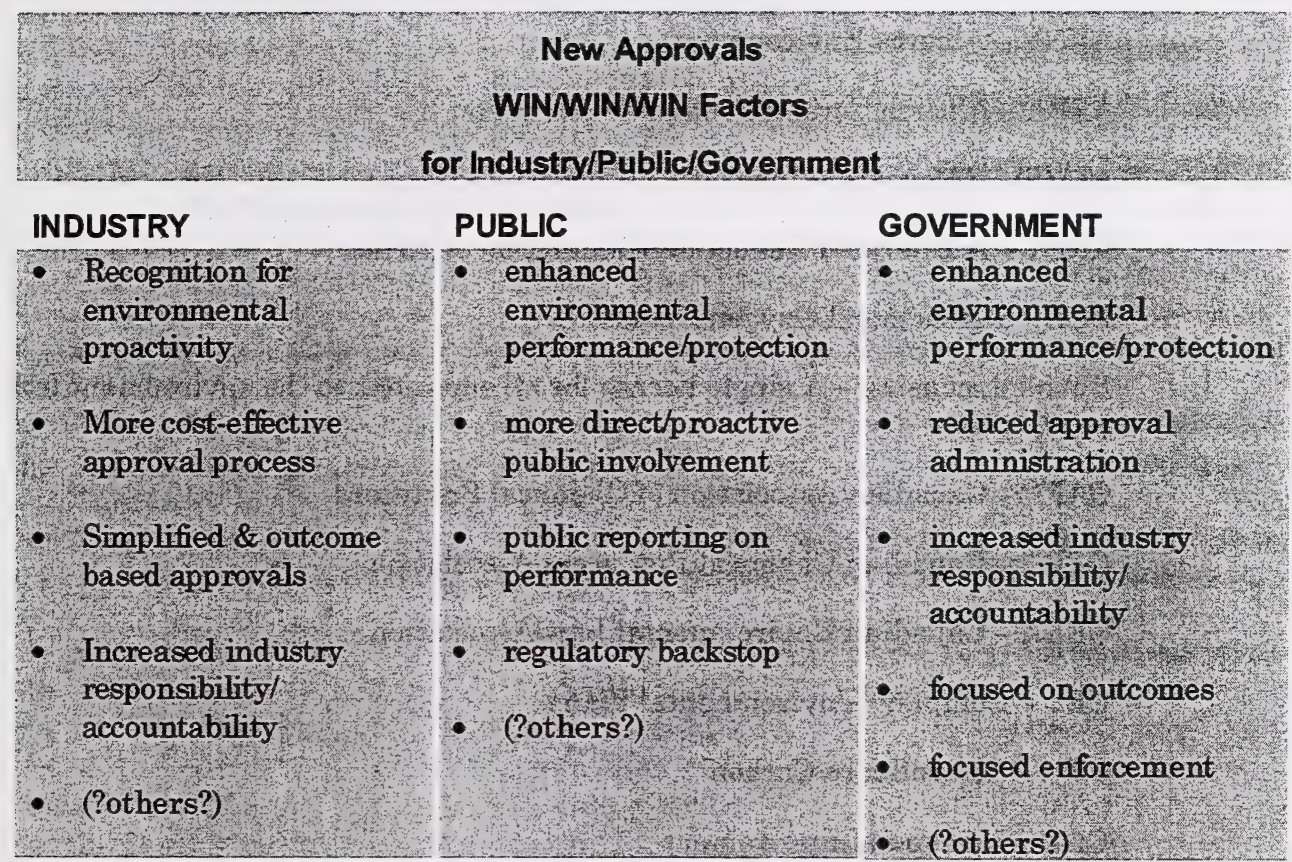




\section{Appendix B - Glossary of Terms and Acronyms}

AENV - Alberta Environment

AFPA - Alberta Forsest Products Association

AIA(S) - Alternative/Innovative Approval (System)

ARET - Accelerated Reduction/Elimination of Toxics

BOD - Biochemical Oxygen Demand

Bubble Licensing - A single license for all emissions to the environment from one facility.

CAPP - Canadian Association of Chemical Producers

CCPA - Canadian Chemical Producers Association

CELA - Canadian Environmental Law Association

CEP - Company Environmental Plans

CFC - Chlorofluoro Carbon

CI - Continuous Improvement

EC - Environment Canada

EIA - Environmental Impact Assessment

EIP - Environmental Improvement Plan

EMS - Environmental Management System

ENGO - Environmental Non-Government Organization

EPA - United States Environmental Protection Agency or State of Victoria (Australia) Environmental Protection Authority

EPEA - Environmental Protection and Enhancement Act (Alberta)

EUB - Energy and Utilities Board (Alberta)

HAPS - Hazardous Air Pollutants

Headroom - The net difference between the license compliance limit (for a parameter) and the normal emission/effluent performance of the facility.

IEO - Integrated Environmental Objectives 
ISO 14000

MOE - Ministry of Environment (Ontario)

MOU - Memorandum of Understanding

MSWG - Multi-State Working Group

NDG - New Directions Group

NPRI - National Pollution Release Inventory

PIAD - Pembina Institute for Appropriate Development

P2 - Pollution Prevention

Ratchet - The lowering of the compliance limit for a parameter(s), based on previous demonstrated performance, at the time of pemit/license renewal. Ratchetting - the tendency to do so over successive permit renewals.

SAC - Study Advisory Committee

TSS - Total Suspended Solids

US EPA - United States Environmental Protection Agency

VA - Voluntary Agreements

VCR - Voluntary Challenge Registry

VOC - Volatile Organic Compound 

National Library of Canada
Bibliotheqque nationale du Canada

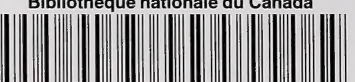

33286520947710 